To summarize : diathermy is of proved value in the treatment of acute and subacute glaucoma, and in the majority of cases is effective in relieving pain in any eye disease. In any condition in which it is desirable to apply heat, it affords us a very convenient and the most efficient means to this end.

\title{
THE REFRACTIVE ERROR OF TWINS
}

BY

\section{FRANK W. LAW}

IN this Journal in $1932 \mathrm{Wilson}^{1}$ presented a short but interesting report upon the eye defects of twins, and suggested the value of further information on the matter. Since that time I have come across eight pairs of presumably monozygotic twins, and give here the results of their ophthalmic examination.

Although the patients were submitted to a general physical examination, it is readily admitted that a specialist's knowledge is essential for the final decision as to whether twins are or are not monozygotic. Accordingly, in order to be on the safe side, those twins considered to be monozygotic have not been so labelled, but the less committal term "identical" has been used instead. Three pairs of dissimilar twins were examined, and the results recorded for purposes of comparison.

Identical.

$$
\text { Age R.E. L.E. Remarks }
$$

1. G.E.N. के $21-0.75$ S. $-0{ }^{\circ} 75$ C. $\rightarrow-1^{\circ} 0$ S.

J.H.N. $-2 \cdot 25 \mathrm{~S}$. $-2 \cdot 25 \mathrm{~S}$.

2. I..G. $\quad$ \& $8+3^{\circ} 0 \mathrm{~S} .+2^{\circ} 0 \mathrm{C} . \downarrow+3^{\circ} \mathrm{S} .+1^{\circ} 0 \mathrm{C} . \downarrow$ Both R.C.C.S.

R.G. $\quad+1^{\circ} 0 \mathrm{~S} .+3^{\circ} 0 \mathrm{C} . \downarrow+2^{\circ} 0 \mathrm{~S} .+0^{\circ} 5 \mathrm{C} . \downarrow$ Mother albinoid, with nystagmus.
3. R.C. क $5 \frac{1}{2}+2 \cdot 5 \mathrm{~S}$. $+3 \cdot 25 \mathrm{~S}$.
J.C. $+20 \mathrm{~S}$. $+2{ }^{\circ} \mathrm{OS}$.
"Occasional squint."
R.C.C.S. $20^{\circ}$.

4. D.L. \& $9+1 \cdot 5 \mathrm{~S}$. $+1 \cdot 5 \mathrm{~S}$.
B.L. $+1.5 \mathrm{~S}$. $+1.5 \mathrm{~S}$.
5. D.H. \& $14+0.5 \mathrm{~S}$. $+0.5 \mathrm{~S}$.
J.H. $\quad+0.75 \mathrm{~S} . \quad+0.5 \mathrm{~S} .+0.25 \mathrm{C} . \downarrow$

Right handed. Both L.C.C.S. at 18 mos.

Left handed.

6. J.C. $\quad$ o $3+2.5 \mathrm{~S} .+0{ }^{\circ} \mathrm{C} \rightarrow+2.0 \mathrm{~S} .+0.5 \mathrm{C} \rightarrow$

Both occasional divergence without glasses.

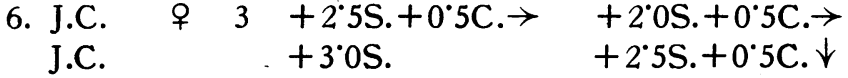

R.C.C.S. $10^{\circ}$.

7. A.W. \& $7+3^{\circ} 0 \mathrm{~S} .+2.0 \mathrm{C} .>+3^{\circ} 0 \mathrm{~S} .+2^{\circ} 0 \mathrm{C} .<$ E.W. $\quad+3.0 \mathrm{~S} .+2{ }^{\circ} \mathrm{C} .>+3.0 \mathrm{~S} .+1^{\circ} 0 \mathrm{C} . K$
8. J.W. \& $8+20 \mathrm{~S}$. J.W. $\quad+0.5 \mathrm{~S} .+0{ }^{\circ} 5 \mathrm{C} . \downarrow+0{ }^{\circ} \downarrow \mathrm{S} .+0{ }^{\circ} 5 \mathrm{C} . \downarrow$

Slight disparity in size. 
Dissimilar.

$$
\begin{aligned}
& \text { Age R.E. L.E. } \\
& \text { 9. R.W. \& } 6+0.5 \mathrm{~S} .+0.5 \mathrm{C} . \downarrow+0.5 \mathrm{~S} .+0.5 \mathrm{C} . \downarrow \\
& \text { B.W. }+ \text { + }+20^{\circ} \text {. }+2 \mathrm{~S}^{\circ} \text {. } \\
& \text { 10. J.T. क } 11-1^{\circ} 0 \text { S. }-0.5 \mathrm{C} . \downarrow-20 \text { S. }-0.5 \mathrm{C} . \downarrow \\
& \text { M.T. \& }-1^{\circ} 5 \mathrm{~S} .+4^{\circ} \mathrm{C} \text { C. } \downarrow-2.0 \mathrm{~S} .+5^{\circ} \mathrm{CC} . k \\
& \text { 11. W W. \& } 13-0.5 \mathrm{C} . \rightarrow \quad-0.5 \mathrm{C} . \rightarrow \\
& \text { I.W. \& }-0.25 \mathrm{~S} \text {. } \quad+0.25 \mathrm{~S} \text {. }
\end{aligned}
$$

Adopting Wilson's classification, pairs 4,5 and 6 may be con $\frac{\vec{\omega}}{\infty}$ sidered alike, having $0.5 \mathrm{D}$. or less of difference; pairs 3 and 70 have between $0.5 \mathrm{D}$ and $1 \mathrm{D}$. of difference; and pairs 1,2 and 8 are quite different. The three dissimilar pairs have totally dissimilar refractions.

For comparative purposes Wilson collected a record of the refractive errors of 50 pairs of brothers and sisters born at different ${ }_{-}$ times, and not related to twins. A comparison of all these figurest is given below.

$\begin{array}{llll} & \text { F.W.L. } & \text { F.W.L. } & \text { J.A.W } \\ \text { Cases alike - } & 37.5 \% & - & 25 \% \\ \text { Cases apparently alike } & 25 \% & - & 33.5 \% \\ \text { Cas€s with more than } & & & \\ \text { 1D. of difference - } & 37.5 \% & 100 \% & 41.5 \%\end{array}$

In his two tables Wilson has slightly altered his standard foro the first group. When dealing with twins he considered as alike $\stackrel{\odot}{\stackrel{\odot}{\circ}}$ only those with exactly identical refractions, whereas with the $\overrightarrow{0}$ brothers and sisters his first group included those "alike or with? only $0.5 \mathrm{D}$. of difference." I have adopted the latter standardf in my grouping; the difference between our percentage figures may very well arise from this cause.

It is interesting to consider the occurrence of squint in these cases-surely higher than in an unselected list of refraction cases $\stackrel{3}{3}$. Of my eight cases, no less than four pairs were squinters, ando one member of another pair had a slight convergence. In Wilson's list of 12 pairs, there were four pairs of squinters, and twos individual members; all of his cases of strabismus were convergent, whereas one of my pairs was divergent.

The numbers are admittedly small, and percentages are reallyc్ not justified; but it is suggested that these conclusions may ben drawn : (1) That pairs of identical twins have by no means always

* In his paper Wilson states that as the pairs are of like sex and as in severak pairs the retinoscopies are alike, it is reasonable to assume that one half aro monozygotic; I have adopted the opposite method of determining the fact that theD twins were monozygotic or at least identical, and then examining the refractive errors. 
identical refractions; (2) that the refractions in the case of identical twins are alike at least twice as often as they are in the case of brothers and sisters of the same family born at different times; (3) the occurrence of strabismus is higher in twins than in sibs of different ages--it occurs sometimes in one member of the pair only, but far more commonly in both members, and then is of the same nature and direction in each.

REFERENCE

Wilson, J. A.-Twins with eye defects. Ametropia and Strabismus. Brit. Jl. of Ophthal., Vol. XVI, p. 421, July, 1932.

\title{
SOME PRACTICAL POINTS IN THE TREATMENT OF SIMPLE DETACHMENT OF THE RETINA
}

\author{
BY \\ HAROLD RIDLEY \\ SENIOR RESIDENT OFFICER, MOORFIELDS EYE HOSPITAL
}

OF late, with improvements in technique, operations for detachment of the retina have become much more frequent. Though at the moment diathermy operations are in almost universal favour, there is considerable variation in method and application, and a few notes based on first-hand experience, either as operator or assistant, of a large number of cases recently dealt with at Moorfields may be of interest.

The problem, like any other in surgery, consists of two partsdiagnosis and treatment. From the surgical aspect a simple retinal detachment should be regarded as a secondary lesion following a retinal tear, and on this latter our attention must be concentrated. Diagnosis consists of localization of the hole.

Localization of the hole may be simple or very difficult. In many cases a very shrewd idea can be obtained even without the use of the ophthalmoscope. A patient seen wearing a high myopic correction is most likely to have a large tear in the upper half of the retina some distance from the periphery; an emmetrope or hypermetrope a disinsertion in the lower temporal quadrant. The patient's history, if reliable, is of great importance; for instance, flashes of light in the lower nasal field followed by a shadow beginning in the same situation is almost pathognomonic of a hole in the upper temporal quadrant. Unfortunately, a shadow beginning in the upper half of the field is not such a reliable guide to the situation of the hole, for subretinal fluid leaking through a hole above tends to sink under the action of gravity 